\title{
Addendum
}

\section{A Green and Straightforward Synthesis of 4'-Substituted Terpyridines}

\author{
Andreas Winter, Antje M. J. van den Berg, Richard Hoogenboom, Guido Kickelbick, Ulrich S. Schubert* \\ Synthesis 2006, 2873.
}

\begin{abstract}
A part of the sentence in the fourth paragraph describing a previously published closely related synthesis of pyridylsubstituted 2,2':6',2"'-terpyridines using PEG300 as solvent by C. B. Smith, C. L. Raston and A. N. Sobolev (Green Chem. 2005, 650) was unfortunately deleted in the production process, leading to a false impression of the origin of the synthetic strategy. The correct paragraph is given below:

'As a part of our work on the development of novel metallopolymers we have chosen poly(ethylene glycol) (PEG) as a versatile solvent for the efficient synthesis of substituted and functionalized terpyridine units $\mathbf{1}$ (see ref. 13 for a recent example by Raston et al.). ${ }^{13}$ Due to its non-toxicity, PEG has become a popular reaction medium in synthetic chemistry over the last number of years. ${ }^{14}$ Furthermore, this solvent fully meets the demands of green chemistry, ${ }^{15}$ as it is highly water-miscible and also potentially recyclable.'

Furthermore, the following references to additional prior work in this field should be added to reference 11: (b) Cave, G. W. V.; Raston C. L. J. Chem. Soc., Perkin Trans. 1 2001, 3258. (c) Cave, G. W. V.; Raston, C. L., Scott, J. L. Chem. Commun. 2001, 2159. (d) Rothenberg, G.; Downie, A. P.; Raston, C. L.; Scott, J. L. J. Am. Chem. Soc. $2001,123,8701$. (e) Cave, G. W. V.; Hardie, M. J.; Roberts, B. A.; Raston, C. L. Eur. J. Org. Chem. 2001, 3227. (f) Raston, C. L.; Scott, J. L. Green Chem. 2000, 49. (g) Husson, J.; Migianu, E.; Beley, M.; Kirsch, G. Synthesis 2004, 267. (h) Cave, G. W. V.; Raston, C. L. J. Chem. Educ. 2005, 82, 468. We thank Dr. Christopher B. Smith for pointing out the related contributions to us.
\end{abstract}

